\title{
The Serological Comparison of Strains of Influenza Virus
}

\author{
By F. FULTON AND K. R. DUMBELL \\ The National Institute for Medical Research, Hampstead, \\ London, N.W. 3
}

SUMMARY: The antigens of eight strains of influenza virus were compared by a simple and economical complement-fixation technique in which drops on Perspex sheets replaced larger volumes of reagents in racks of tubes. By this means more extensive tests were made with a limited supply of material than by standard tube techniques.

The specific antisera were prepared in mice, thus avoiding the elaborate isolation precautions necessary for ferrets, and sera from large groups were pooled to minimize individual variations between animals. The antigens were standardized in terms of the amount of complement fixed in the presence of excess homologous antiserum. The comparison of the strains is presented in the form of index numbers, ranging from 0 to $1.0 ; 1.0$ represents complete identity of two strains, while the smaller numbers are taken to represent the degree of antigenic relationship between strains. Of the six strains examined which were isolated in different years, all were serologically distinct though the two B strains were closely similar and two of the A strains were fairly closely related. On the other hand, the three strains of influenza $A$ virus isolated in 1947, two in London and one in the U.S.A., were identical.

Knowledge of the antigenic differences between strains of influenza virus is important both in the study of the epidemiology of influenza and in the choice of the best components for a vaccine. Most comparisons have been made in one of three ways. The first method, using the chick red cell agglutination phenomenon (Hirst, 1943), has the advantage of an apparent simplicity. This is apt to be somewhat misleading, for not only do different batches of red cells vary in behaviour (Stuart-Harris, 1943), but variations in avidity of the antigen must also be taken into account. Furthermore, haemagglutination by some freshly isolated strains of virus is inhibited by normal serum (Francis, Salk \& Brace, 1946). To crown all these difficulties any 'reasonable' answers can only be obtained by assuming a law of reciprocal relations between any two virus strains.

The other methods of comparison are by cross-immunization or by the serum neutralization test in mice (Francis \& Magill, 1938; Magill \& Francis, 1938; Smith \& Andrewes, 1938). The possible fallacy in these methods is that all the strains need to be mouse adapted, and Hirst (1947) has recently shown that adaption to mice entails the replacement of the strain growing in eggs by another variant which may be antigenically different from the 'egg' virus. Moreover, persistent failure has met all attempts to adapt certain strains of influenza $B$ virus to mice.

The complement-fixation test is more difficult to perform, but this added labour is in our opinion justified by the superiority of the results obtained. This paper describes a method of conducting the test so that strains of influenza virus may be compared with precision. 


\section{MATERIAL AND METHODS}

For an adequate titration it is essential to be able to vary both the serum dilutions and the antigen dilutions in a 'chess-board' experiment. Such tests demand a large number of tubes as well as considerable volumes of reagents. When either of the reagents is anticomplementary in the zones in which the titration must be conducted, it becomes also necessary to vary the complement, and it is impossible to make such a test without splitting every experiment into a number of orientating approaches so that the final test is a selection of the variables designed to give the maximum information with a reasonable number of tubes. In order to be able to carry out spaciously conceived tests without this wearisome preliminary orientation, we have designed a complementfixation test so that the reaction is carried out not in tubes, but in drops on Perspex sheets.

\section{Apparatus}

Perspex sheets. The Perspex sheets were 16 in. square and $\frac{1}{8}$ in. thick. The top surface of the sheet was engraved with a centrally placed grid of $144 \mathrm{in}$. squares in 12 rows of 12 . The rows of squares were numbered along the lefthand margin 1 to 12 from top to bottom, and the columns were numbered along the top margin from left to right $a$ to $n$, omitting $i$ and $l$. Twelve such plates were made, and each was marked with a letter $A$ to $L$ inclusive(Pl. 1, fig. 1).

Rack. A rack was constructed to hold these twelve Perspex sheets in the horizontal position. It was made of laminated bakelite and brass tubing, stood on brass legs 2 in. long and had a carrying handle at the top. The Perspex sheets could be slid on to their narrow supporting shelves and were held $\frac{5}{8}$ in. apart. The sheets were held in position by inserting a metal rod ( $\mathrm{Pl}$. 1, fig. 2).

Boxes. Two identical boxes were made of sheet brass to accommodate this rack. They were constructed with a top flange covered with rubber so that by screwing down the lid they could be made airtight. The boxes were kept saturated with water vapour by putting a layer of absorbent cotton-wool in the bottom and keeping this moist with distilled water. One of the boxes was held in a refrigerator at $4^{\circ}$, and the other in a hot-room at $37^{\circ}$.

Dropping pipettes. Dropping pipettes were made to deliver $20 \mathrm{~mm} .{ }^{3}$ of water (Morse gauge 57) and $40 \mathrm{~mm} .^{3}$ of water (Morse gauge 43). The delivery of these volumes was found to be sufficiently accurate over the whole range of reagent dilutions used, irrespective of their varying surface tensions.

\section{Reagents}

Strains. The following strains were examined.

Influenza A: PR 8, WS (both mouse adapted); Barratt (BAR), Williams (WIL)-isolated London, 1947; Rhodes (RHO)-isolated U.S.A., 1947.

Influenza B: Lee (mouse adapted); Crawley (CRA)-isolated London 1946. Swine influenza: Shope 15 (mouse adapted).

The strains were stored as infected allantoic fluids mixed with an equal volume of $10 \%$ horse-serum broth and kept in sealed glass ampoules at $-76^{\circ}$.

It is necessary to emphasize that at the present time many of the classical 
influenza strains have had so varied a history that it cannot be assumed, for instance, that the strain called PR 8 in this laboratory is now identical with PR 8 strains used in laboratories in other parts of the world.

Antigens. Allantoic fluids infected with influenza virus contain two complement-fixing antigens (Friedewald, 1943; Wiener, Henle \& Henle, 1946). One antigen is associated with the elementary body and is strain specific, the other is the soluble antigen which is group specific. For our purpose the elementary body antigen alone is required. The stored, infected, allantoic fluids were diluted $10^{-2}$ in $0.85 \%$ saline and passed intra-allantoically to 10-day chick embryos. After $48 \mathrm{hr}$. at $35^{\circ}$ the virus was harvested. The elementary bodies were partially purified and concentrated five-fold by absorption and elution from red cells by the method of Francis \& Salk (1942). The Shope strain could not be satisfactorily eluted (Burnet, Beveridge, McEwin \& Boake, 1945), and so with this strain the infected allantoic fluids were harvested bloodlessly and the elementary bodies partially purified and concentrated by high-speed centrifugation.

The eluted elementary bodies in physiological saline were tested for haemagglutination by the Salk pattern test (Salk, 1944), using a final concentration of chick cells of $0.25 \%$. The titres ranged from $1 / 1000$ to $1 / 4000$. The antigens were stored in sealed glass ampoules at $-76^{\circ}$.

Antisera. Immune mouse sera were used, the mice being infected with allantoic fluid given intranasally. In the past it has been usual to use immune ferret sera in the antigenic analysis of strains of influenza virus, but mouse sera possess several advantages. As a pool from at least forty mice is used, individual variations are minimized, and further, as cross-infection cannot be demonstrated among mice kept in different cages (Laidlaw, Smith, Andrewes \& Dunkin, 1935) it is possible to prepare sera from a number of different strains without adopting the strict isolation procedures which would be necessary with ferrets. In addition, mouse sera contain no natural haemolysins for sheep cells.

The infected allantoic fluids of the mouse-adapted strains were diluted so that they would cause very few deaths but would produce some consolidation of the lungs. Usually such fluids were diluted $10^{-5}$ in saline, and $0.05 \mathrm{ml}$. was given intranasally.

With the unadapted A strains the infected allantoic fluid was passaged undiluted. Although there was no obvious change in the lungs of the mice, potent immune sera were obtained. That multiplication of the virus does in fact take place has been demonstrated by Hirst (1947), and is also shown by the fact that there is no antigenic response if the virus in the allantoic fluid is first killed with formalin.

With the unadapted B strain (CRA) undiluted allantoic fluid killed most of the mice and so the fluid was given diluted $10^{-2}$.

After 13 days the mice were bled from the heart, the pooled blood was allowed to clot and then centrifuged at 18,000 r.p.m. for $15 \mathrm{~min}$. The clear serum was dispensed into glass ampoules which were sealed and stored at $-76^{\circ}$. Since mouse serum lacks the $C^{2}$ component of complement 
(Brown, 1943), it might be supposed that inactivation would be unnecessary. In fact, unheated mouse serum was strongly anticomplementary and, moreover, fixed more complement in the presence of influenza antigens. To avoid these non-specific fixations the sera must be heated. Casals \& Palacios (1941) have shown in the titration of other antibodies in mouse sera that the optimum inactivation temperature is $60^{\circ}$. However, at this temperature, the influenza antibodies are rapidly destroyed. Throughout this work the mouse sera were inactivated immediately before use for $30 \mathrm{~min}$. at $55^{\circ}$.

Complement. The complement was pooled guinea-pig serum stored in sealed glass ampoules at $-76^{\circ}$.

Diluent. The diluent was based on the data of Mayer, Osler, Bier \& Heidelberger (1946). Stock: $\mathrm{NaCl} 85 \cdot 0$ g.; 5,5-diethylbarbituric acid 5•75 g.; sodium5,5-diethylbarbiturate $3.75 \mathrm{~g}$. Dissolve the acid in $500 \mathrm{ml}$. of hot glassdistilled water, add the other components and make up to $2000 \mathrm{ml}$; then add $\mathrm{MgCl}_{2} 6 \mathrm{H}_{2} \mathrm{O} 1.68 \mathrm{~g}$. and $\mathrm{CaCl}_{2} \mathbf{0} \cdot 28 \mathrm{~g}$. Autoclave at $15 \mathrm{lb}$./sq.in. for $20 \mathrm{~min}$., $\mathrm{pH}=7 \cdot 2$. Store at $4^{\circ}$. For use the stock is diluted $1 / 5$ in glass-distilled water.

Sensitized sheep erythrocytes. Sheep blood was stored in Alsever's solution and used for periods up to 4 months (Bukantz, Rein \& Kent, 1946). Immediately before use the cells were washed three times, diluted to approximately $0.2 \%$ and then accurately standardized in a photoelectric densitometer. The cells were maximally sensitized by the method of Wadsworth, Maltaner \& Maltaner (1938), which, using Burroughs Wellcome haemolysin, entailed adding to the cell suspension an equal volume of haemolysin diluted 1/400. Sensitization was allowed to proceed for $1 \mathrm{hr}$. at $37^{\circ}$.

\section{Conduct of the test}

To illustrate the method a titration of a PR 8 immune mouse serum is presented in detail. In test-tubes a series of eleven twofold dilutions of the serum are made, from $1 / 1$ to $1 / 1024$, and sixteen dilutions of complement as in Table 1. To provide enough of these dilutions for twelve Perspex sheets, only $1.7 \mathrm{ml}$. of guinea-pig serum is required. The antigen dilution is also prepared, in this case so as to contain 1000 haemagglutination units.

A Perspex sheet (say B) is laid on the bench. Using a $20 \mathrm{~mm} \cdot{ }^{3}$ dropping pipette the serum dilutions are first distributed. Row 12 receives one drop of diluent (control row), row 11 receives one drop of serum dilution 1/1024, row 10 receives one drop of serum dilution $1 / 512$, and so on. Then to each square is added a drop of the appropriate complement dilution according to the scheme in Table 1. Finally, a drop of diluent is added to the pool in each square, as B is the serum control sheet. No deliberate mixing of the drops is necessary. Another Perspex sheet (say C) is similarly prepared except that the third drop of each pool is the antigen.

Each sheet takes about $12 \mathrm{~min}$. to set out, and as it is completed it is put away in the rack which is already inside the box in the cold room. When the last plate has been inserted the top of the box is screwed down and left to stand overnight. Next day the rack is removed from the cold room. To each square 
on the Perspex sheets $40 \mathrm{~mm} .^{3}$ of sensitized sheep cells are added with a dropping pipette. Again no mixing is required. The sheets in the rack are now transferred to the water-saturated box in the $37^{\circ}$ hot room, and the lid screwed down. At the end of $2 \mathrm{hr}$. the rack is removed from the box and allowed to stand at room temperature for half an hour or so, to allow the surface film of moisture to evaporate from the sheets.

Table 1. Complement dilution table, with scheme for the distribution of the complement dilutions on Perspex sheets

\begin{tabular}{|c|c|c|c|c|c|c|}
\hline \multirow[b]{2}{*}{ Tube no. } & \multirow[b]{2}{*}{ Dilution 1 in } & \multirow[b]{2}{*}{$\mathrm{mm}^{3 *}$} & \multirow[b]{2}{*}{$\log _{10} \mathrm{~mm} .^{3}$} & \multicolumn{3}{|c|}{$\begin{array}{c}\text { Distribution on Perspex sheets } \\
\text { Columns }\end{array}$} \\
\hline & & & & Row 1-3 & Row 4-7 & Kow 8-12 \\
\hline 1 & $3 \cdot 2$ & $6 \cdot 3$ & 0.8 & $a$ & - & - \\
\hline 2 & 5 & $4 \cdot 0$ & 0.6 & $b$ & - & - \\
\hline 3 & 8 & $2 \cdot 5$ & 0.4 & $c$ & $a$ & - \\
\hline 4 & $12 \cdot 6$ & $1 \cdot 6$ & $0 \cdot 2$ & $d$ & $b$ & - \\
\hline 5 & 20 & $1 \cdot 0$ & 0.0 & $e$ & $c$ & $a$ \\
\hline 6 & 32 & $0 \cdot 63$ & $1 \cdot 8$ & $f$ & $d$ & $b$ \\
\hline 7 & 50 & 0.4 & $\overline{1} \cdot 6$ & $g$ & $e$ & $c$ \\
\hline 8 & 80 & 0.25 & $\overline{1} \cdot 4$ & h & $f$ & $d$ \\
\hline 9 & 100 & 0.2 & $\overline{1} \cdot 3$ & - & - & $e$ \\
\hline 10 & 126 & $0 \cdot 16$ & $\overline{1} \cdot 2$ & $j$ & $g$ & $f$ \\
\hline 11 & 159 & $0 \cdot 13$ & $\overline{\mathbf{1}} \cdot \mathbf{1}$ & - & - & $g$ \\
\hline 12 & 200 & $0 \cdot 10$ & $\overline{1} \cdot 0$ & $k$ & $h$ & $h$ \\
\hline 13 & 250 & 0.08 & $2 \cdot 9$ & - & $j$ & $j$ \\
\hline 14 & 316 & 0.06 & $\mathbf{2} \cdot \mathbf{8}$ & $m$ & $k$ & $k$ \\
\hline 15 & 400 & 0.05 & $\overline{2} \cdot 7$ & - & $m$ & $m$ \\
\hline 16 & 500 & 0.04 & $\overline{2} \cdot 6$ & $n$ & $n$ & $n$ \\
\hline
\end{tabular}

The test is read by placing the Perspex sheets flat on a white background with a strong light overhead. Where the cells have not been haemolysed they collect in a central dot (Pl. 1, fig. 3), rather as the cells in the control tube collect in a button at the bottom of the tube in the Salk test.

By observing the density of this dot, the end-point is taken as that square which by inspection shows half the cells haemolyzed. With the complement intervals chosen this point is usually sharp and easy to assess. Frequently one square shows complete haemolysis and the next no haemolysis, in which case the end-point is taken as the geometric mean of the amounts of complement in the two squares.

The data are given in Table 2. On the serum control sheet, $\mathrm{B}$, the square for $50 \%$ haemolysis is noted for each serum dilution. From this the amount of complement required is obtained by reference to Table 1 . In the same way on sheet $\mathrm{C}$ the amounts of complement required for $50 \%$ haemolysis in the presence of antigen are noted. By subtracting the first value from the second, the amount of complement fixed in the antigen-antibody reaction is obtained. The unit is taken as the minimal amount of complement needed to produce $50 \%$ haemolysis in the presence of the antigen, in this case $0.05 \mathrm{~mm} .^{3}$ Dividing the $\mathrm{mm} .^{3}$ of complement fixed by 0.05 , we obtain the number of units fixed 
at each serum dilution, here expressed as the logarithm. In Fig. 1 (solid line) the log units fixed have been plotted against log serum-dilutions. Parallel tests have shown that the fixation on the sheets is identical with that occurring in tubes using the same reagents but with $200 \mathrm{~mm} .{ }^{3}$ volumes in the tubes instead of $20 \mathrm{~mm} .^{3}$ drops. In Fig. 1 and in subsequent tests the undiluted serum is

Table 2. Complement fixation of PR 8 immune serum with 1000 haemagglutinin units of homologous antigen. Calculation of the log-units fixed

\begin{tabular}{|c|c|c|c|c|c|c|}
\hline \multirow[b]{2}{*}{ Row } & \multirow{2}{*}{$\begin{array}{l}\text { Serum } \\
\text { dilution } \\
\text { one in }\end{array}$} & \multirow{2}{*}{$\begin{array}{c}\text { B, serum } \\
\text { control } \\
\mathrm{mm}^{8} \mathrm{C} \\
(x)\end{array}$} & \multicolumn{4}{|c|}{$C$, antigen 1000 units } \\
\hline & & & $\underset{(y)}{\mathrm{mm}^{3} C}$ & $(y-x)$ & $\begin{array}{c}\log _{10}(y-x) \\
(z)\end{array}$ & $\begin{array}{c}\log _{10} \text { units } \\
(z-\overline{2} \cdot 7)\end{array}$ \\
\hline 1 & $\mathbf{1}$ & $1 \cdot 0$ & $4 \cdot 0$ & $3 \cdot 0$ & $0 \cdot 48$ & $1 \cdot 78$ \\
\hline 2 & 2 & $0 \cdot 4$ & $\mathbf{3 \cdot 2}$ & $2 \cdot 8$ & 0.45 & 1.75 \\
\hline 3 & 4 & $\mathbf{0 . 2 5}$ & $2 \cdot 5$ & $2 \cdot 25$ & $0 \cdot 35$ & $1 \cdot 65$ \\
\hline 4 & 8 & $0 \cdot 16$ & $\mathbf{2} \cdot 0$ & 1.84 & $0 \cdot 26$ & $1 \cdot 56$ \\
\hline 5 & 16 & $0 \cdot 10$ & $1 \cdot 3$ & $1 \cdot 20$ & 0.08 & $1 \cdot 38$ \\
\hline 6 & 32 & $0 \cdot 08$ & $0 \cdot 63$ & 0.55 & $\overline{1} \cdot 74$ & 1.04 \\
\hline 7 & 64 & 0.07 & 0.25 & $0 \cdot 18$ & 1.25 & 0.55 \\
\hline 8 & 128 & 0.06 & 0.06 & 0 & - & - \\
\hline 9 & 256 & 0.06 & $0 \cdot 05$ & -0.01 & - & $\ldots$ \\
\hline 10 & 512 & 0.06 & 0.05 & -0.01 & - & - \\
\hline 11 & 1024 & 0.06 & 0.05 & -0.01 & - & - \\
\hline 12 & - & 0.06 & $0.05^{*}$ & -0.01 & - & \\
\hline
\end{tabular}

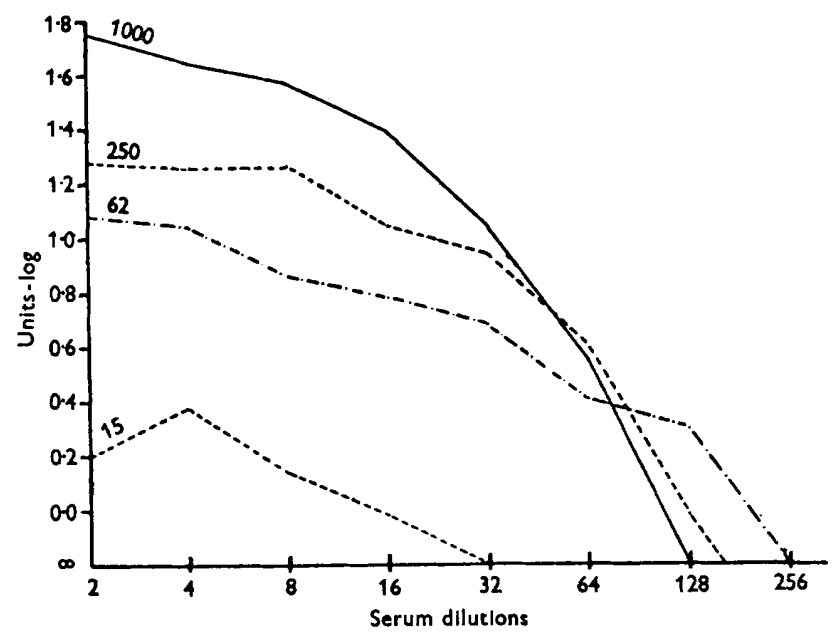

Fig. 1. PR 8 immune serum titrated with four different concentrations of homologous antigen of 1000, 250, 62 and 15 haemagglutinin units.

omitted, for with such strong reagents the number of units fixed in repeated tests is variable; and also, as will be demonstrated, the antibodies in the $1 / 2$ dilution are so greatly in excess of the amounts of antigen available, that no information is gained. By this omission a great saving of serum was effected. 
Miscellaneous precautions. It has been found convenient, when setting out the drops on the Perspex, to use a sheet of brass as a backing plate. This increases the internal reflexions and makes it easier to see how many drops have been placed on a square. At a later stage when the sensitized cells are being added it is preferable to use a backing plate of black bakelite. For reading the test a sheet of white erenoid has been found useful. The exact height from which the drops are delivered on to the Perspex sheet varies slightly with the prevailing humidity. Usually a height of $2-3 \mathrm{~cm}$. is convenient. Occasionally the drops tend to ricochet on one another, but this tendency can be countered by slightly increasing the dropping height. Each sheet is completed and put away in the cold before the next is commenced. This may not be necessary when very few sheets are being set up, but in our experience of large series too much evaporation occurs if the sheets are left in the laboratory during the whole procedure. Even in the water-saturated box at $4^{\circ}$, a certain amount of evaporation does occur overnight, but this is not sufficiently marked to affect the complement, although no doubt if it could be entirely avoided the complement titre would be slightly higher. It has been found that even when the reaction is carried out in the usual manner in test-tubes with fixation for $18 \mathrm{hr}$. in the cold, a slightly higher complement titre is obtained by preventing surface evaporation by a layer of liquid paraffin in each tube.

In the design of the rack the space between the individual sheets is $\frac{5}{8}$ in. This distance should not be decreased very much as, when the plates are too close, there is a tendency for the water in the drops to distil over on to the under-side of the sheet immediately above. It was found that the top sheet in our rack showed a greater degree of evaporation than the other sheets because of the close proximity of the bakelite top of the rack which cooled at a different rate. This was avoided by keeping sheet $\mathbf{A}$ always in position in the rack but not using it in the test. Obviously if the apparatus were redesigned the rack could be suitably modified.

The reading of the test depends, as has been described, on the fact that the unhaemolyzed cells collect in a dot in the centre of the pool. This is presumed to occur because the haemolysin dilution for maximal sensitization is close to the agglutination titre of the haemolysin serum. The effect is enhanced by sensitizing the cells for a full hour before use. Occasionally it will be found that on first reading the cells are not sharply confined to a central dot. In such cases a slight rotary twist of the sheet will clarify the pattern

After reading, the sheets are placed in a large photographic dish and covered with water containing $0.2 \% \mathrm{HCl}$. After $\frac{1}{2} \mathrm{hr}$. or so, they are washed in running cold water, using a swab of absorbent cotton-wool to clean the surface, rinsed in distilled water and placed in the rack which is laid on its side so that the sheets drain vertically. They are left at room temperature to dry overnight and are then stored in a dust-free box. It is important not to rub the dry sheets with a cloth because Perspex easily becomes electrically charged, and it is impossible to deliver drops on to such a sheet; the drops are dragged off the end of the pipette by electrostatic attraction before they have grown to the size expected under the pull of gravity alone. 


\section{The standardization of the antigen}

A PR 8 immune mouse serum was titrated in the manner described, using four different antigen concentrations, measured by haemagglutination, of 1000, 250, 62 and 15 haemagglutinin units (Fig. 1). It will be seen that the antigen concentration determines the maximal amount of complement which can be fixed, because in the stronger concentrations of serum the antibodies are greatly in excess of the binding capacity of even the strongest antigen used. The maximal number of units fixed, is, therefore, independent of the antibody level over a wide range, as is shown by the titration of mouse sera of high and low titres with $\mathbf{2 5 0}$ haemagglutinin units of homologous antigen (Fig. 2).

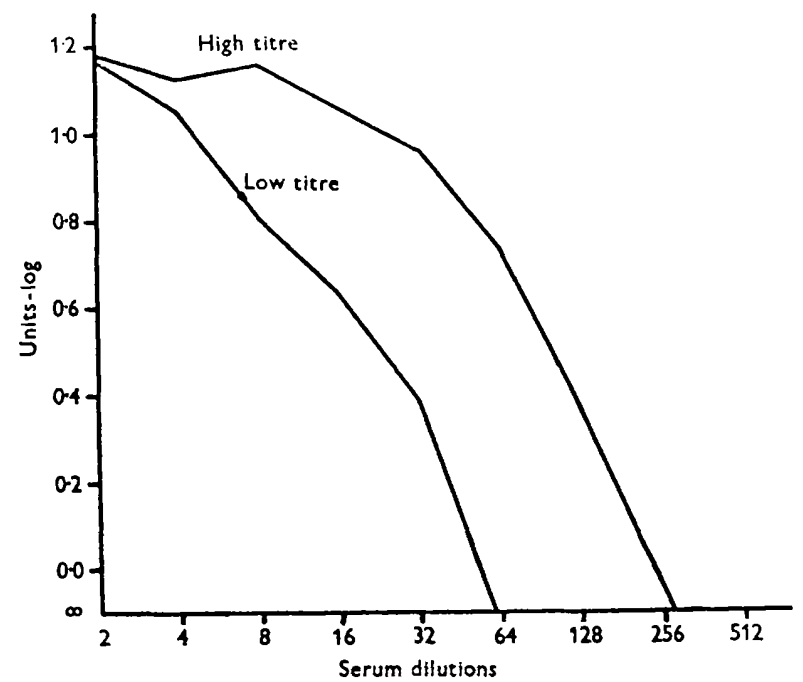

Fig. 2. Titration of two PR 8 immune sera, one of low and one of high titre, with homologous antigen at a concentration of 250 haemagglutinin units.

This observation suggested a simple method of adjusting all the antigens to a standard concentration. For the main test the antigen is used at a constant concentration, arbitrarily chosen so that, in the presence of $1 / 2$ homologous mouse antiserum, the amount of complement maximally fixed shall be $1.0 \mathrm{~mm} .^{3}$ (about $\mathbf{1} \cdot \mathbf{2} \log$ units).

Each antigen is standardized against its homologous antiserum in the following way. Complement dilutions (1-8, Table 1$)$ are prepared in tubes and also antigen dilutions, usually from $1 / 2$ to $1 / 32$. Sufficient inactivated homologous mouse serum is diluted $1 / 2$. Drops of the serum dilution are distributed along six rows (1-6) for the first eight columns. Complement is then added to the columns corresponding with the tube number in Table 1. Finally, to row 6 a drop of the 1/32 antigen is added, to row 5 a drop of the 1/16 antigen and so on, the first row acting as the serum control.

The calculation for PR 8 is shown in Table 3, and the curve is drawn in Fig. 3 with a number of other antigen titrations. In this case the ordinates 
are not $\log$ units but $\mathrm{mm}^{3}$ of complement fixed expressed as the logarithm. From this figure it is easy to determine the antigen concentration required to give a fixation of $1.0 \mathrm{~mm} .^{3}(0 \cdot 0)$.

Table 3. Example of the standardization of a PR8 antigen, with

PR8 Immune Serum $1 / 2$

$\begin{array}{ccccc}\text { Antigen } & \operatorname{mm}^{3} C & (y-0 \cdot 5) & \\ \text { Row } & \text { dilution } 1 \text { in } & (y) & (z) & \log _{10} z \\ 1 & - & 0 \cdot 5 & - & - \\ 2 & 2 & 2 \cdot 0 & 1 \cdot 5 & 0 \cdot 18 \\ 3 & 4 & 1 \cdot 5 & 1 \cdot 0 & 0 \cdot 00 \\ 4 & 8 & 1 \cdot 0 & 0 \cdot 5 & \overline{1} \cdot 70 \\ 5 & 16 & 0 \cdot 8 & 0 \cdot 3 & 1 \cdot 48 \\ 6 & 32 & 0 \cdot 63 & 0 \cdot 13 & \overline{1} \cdot 11 \\ & C=\text { equivalent volume of undiluted complement. }\end{array}$

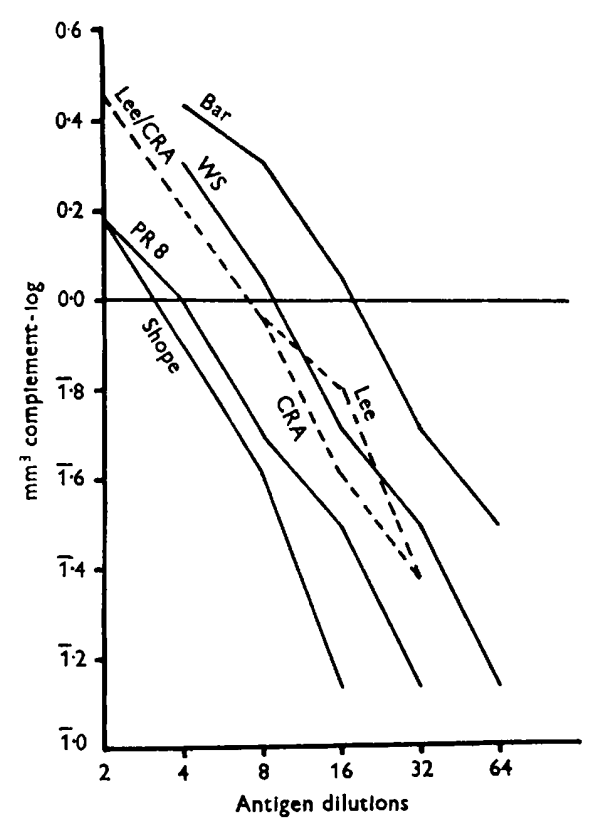

Fig. 3. The standardization of six antigens. See Table 3.

With any one strain it has been found that once the antigen level has been fixed in relation to the haemagglutinin titre, the latter can be used to determine the correct concentration. But the relation between the antigen level and the haemagglutinin level is not the same with every strain (Table 4). We are forced to conclude that the number of particles causing a given standard degree of haemagglutination is not identical in every strain.

\section{Fixation with normal mouse sera}

Antigens of the standard concentration fix a small amount of complement with normal mouse sera, especially in the stronger serum concentrations. This is illustrated in Fig. 4, where a normal mouse serum is titrated first without antigen (solid line) and then with antigen (dotted line). The ordinates here are 
the logarithms of the $\mathrm{mm}^{3}$ of complement fixed. It will be seen that over a considerable range the curve of fixation with antigen is shifted up $\mathbf{0 . 2}$ unit, and this has been found to be true with all the antigens used. On occasion the

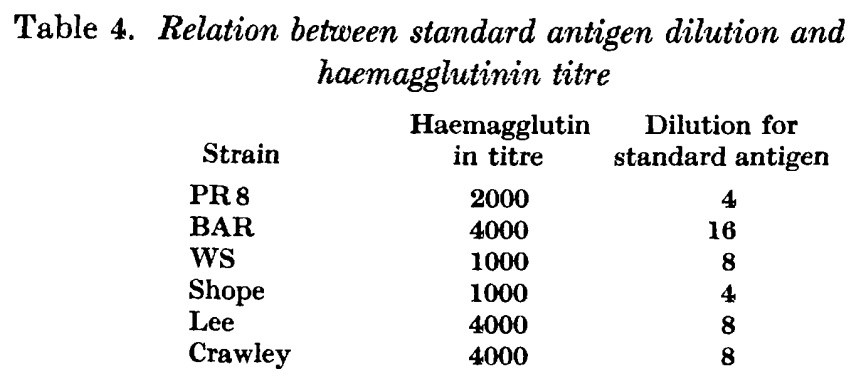

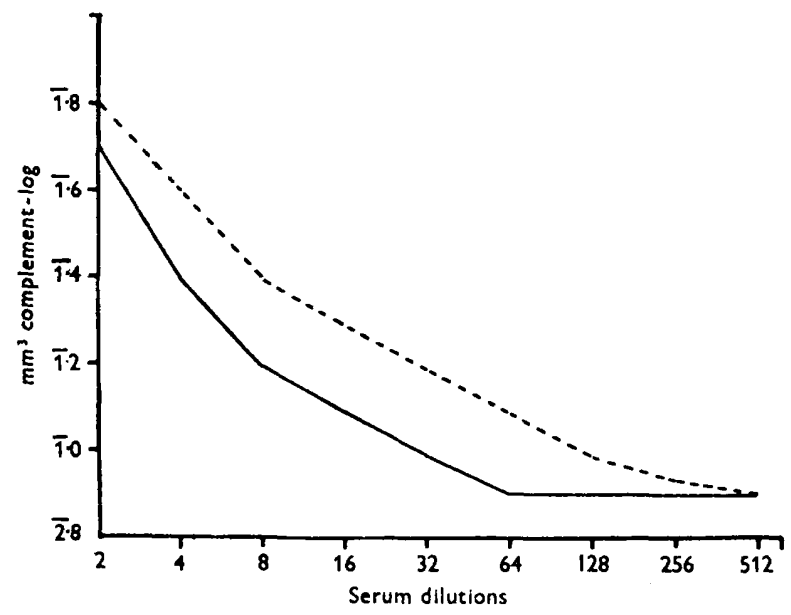

Fig. 4. Fixation of complement by normal mouse serum with standard antigen (dotted line) and without antigen (solid line).

shift is less than this, but it is never more. In any serum titration, therefore, the non-significant fixation is calculated in the manner shown in Table 5. To each value of complement fixed in the serum control, expressed as the logarithm, is added $0 \cdot 2$. These new values are then treated in the way already described and the $\log$ units fixed are calculated. It frequently happens that on the serum-control sheet the amount of complement required for $50 \%$ haemolysis in row 12 (diluent alone) is greater than in the rows immediately above. This is probably due to lack of protective serum, and the unit is calculated on the value in row 11. In the main test any fixation occurring in excess of the calculated non-specific fixation is presumed to be significant.

\section{RESULTS}

The six influenza strains, WS, Barratt, PR8, Shope, Lee and Crawley were compared. To illustrate this comparison the result of the titration of all the antigens against the Lee antiserum is shown in Table 6, and the logarithms of the units fixed have been plotted against the serum dilutions in Fig. 5. 
Each curve is now plotted on stout graph paper, the scale in this case being $18 \mathrm{~mm}$. for the abscissal units and $10 \mathrm{~mm}$. for the units of the ordinate, using 0.0 as a base-line. The area under each curve is estimated by cutting out and weighing the pieces of paper (Table 6, i). This weight in mg. is converted into

Table 5. Calculation of the non-specific complement fixation of a standard antigen

\begin{tabular}{|c|c|c|c|c|c|c|c|}
\hline \multirow{2}{*}{$\begin{array}{l}\text { Serum } \\
\text { dilutions } \\
1 \text { in }\end{array}$} & \multicolumn{2}{|c|}{ Serum control } & \multicolumn{5}{|c|}{ Calculated non-significant fixation } \\
\hline & $\begin{array}{c}\log _{10} \mathrm{~mm} \cdot 3 \\
(a)\end{array}$ & $\underset{(x)}{\mathrm{mm}^{3}}$ & $\begin{array}{c}a+0 \cdot 2 \\
(b)\end{array}$ & $\mathrm{mm}_{(y)}^{\mathrm{s}}$ & $(y-x)$ & $\begin{array}{c}\log _{10}(y-x) \\
(z)\end{array}$ & $\begin{array}{c}\log _{10} \text { units } \\
(z-\overline{2} \cdot 9)\end{array}$ \\
\hline 2 & $\overline{\mathbf{l}} \cdot \boldsymbol{\gamma}$ & 0.5 & $\overline{\mathbf{l}} \cdot \mathbf{9}$ & $0 \cdot 8$ & $0 \cdot 3$ & $1 \cdot 48$ & 0.58 \\
\hline 4 & $\overline{1} \cdot 4$ & $0 \cdot 25$ & $\overline{\mathbf{l}} \cdot \mathbf{6}$ & $0 \cdot 4$ & $0 \cdot 15$ & $1 \cdot 18$ & $\mathbf{0 . 2 8}$ \\
\hline 8 & $\mathbf{I} \cdot \mathbf{2}$ & $0 \cdot 16$ & $\overline{\mathbf{l}} \cdot \mathbf{4}$ & $0 \cdot 25$ & $0 \cdot 09$ & $\mathbf{2} \cdot 95$ & $0 \cdot 05$ \\
\hline 16 & $1 \cdot 1$ & $0 \cdot 13$ & $\mathbf{1} \cdot \mathbf{3}$ & $0 \cdot 20$ & 0.07 & $2 \cdot 84$ & $\cdots$ \\
\hline 32 & $\mathbf{I} \cdot \mathbf{0}$ & $0 \cdot 10$ & $\mathbf{1} \cdot \mathbf{2}$ & $0 \cdot 16$ & $0 \cdot 06$ & $\overline{2} \cdot 78$ & - \\
\hline 64 & $\overline{2} \cdot \theta$ & $0 \cdot 08$ & $\overline{\mathbf{l}} \cdot \mathbf{1}$ & $0 \cdot 13$ & $0 \cdot 05$ & $\mathbf{2} \cdot 70$ & - \\
\hline 128 & $\overline{2} \cdot 9$ & 0.08 & $\overline{\mathbf{1}} \cdot \mathbf{1}$ & $0 \cdot 13$ & 0.05 & $\overline{2} \cdot 70$ & - \\
\hline 256 & $\overline{2} \cdot 9$ & 0.08 & $\tilde{1} \cdot \mathbf{1}$ & $0 \cdot 13$ & 0.05 & $\overline{2} \cdot 70$ & - \\
\hline 512 & $2 \cdot 9$ & $0 \cdot 08$ & $1 \cdot 1$ & $0 \cdot 13$ & 0.05 & $\overline{2} \cdot 70$ & - \\
\hline 1024 & $2 \cdot 9$ & $0 \cdot 08$ & $I \cdot 1$ & $0 \cdot 13$ & 0.05 & $\mathbf{2} \cdot 70$ & - \\
\hline- & $\overline{2} \cdot \theta$ & - & - & - & - & - & - \\
\hline
\end{tabular}

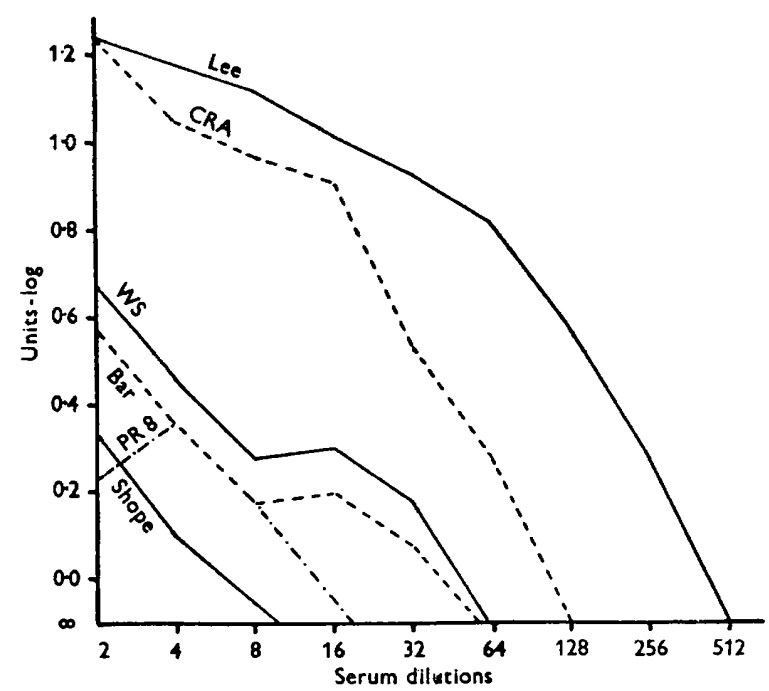

Fig. 5. Lee immune serum titrated with six standard antigens. From data in Table 6.

cm. ${ }^{2}$ by dividing by the weight of $1 \mathrm{~cm} .{ }^{2}$ of the paper used, here $11.5 \mathrm{mg}$. (Table 6, ii). All areas less than the area of the calculated non-specific fixation are disregarded, the rest are expressed as fractions of the homologous area (Table 6, iii, which is ii divided by 120). The areas are reproducible to within about 5-10\%, and the relative areas with different antigens are not affected by slight differences in the titre of different pools of antiserum.

The comparison of all the antigens with antisera prepared against them is 
shown in Table $7 a$. It will be seen that the cross-reactions are not reciprocal, and therefore to show the relationship between the strains the two fractions are summed and divided by 2 (Table $7 b$ ). For example, the cross-reactions

Table 6. Complement fixation of Lee immune serum with six standard antigens. Calculation of index numbers

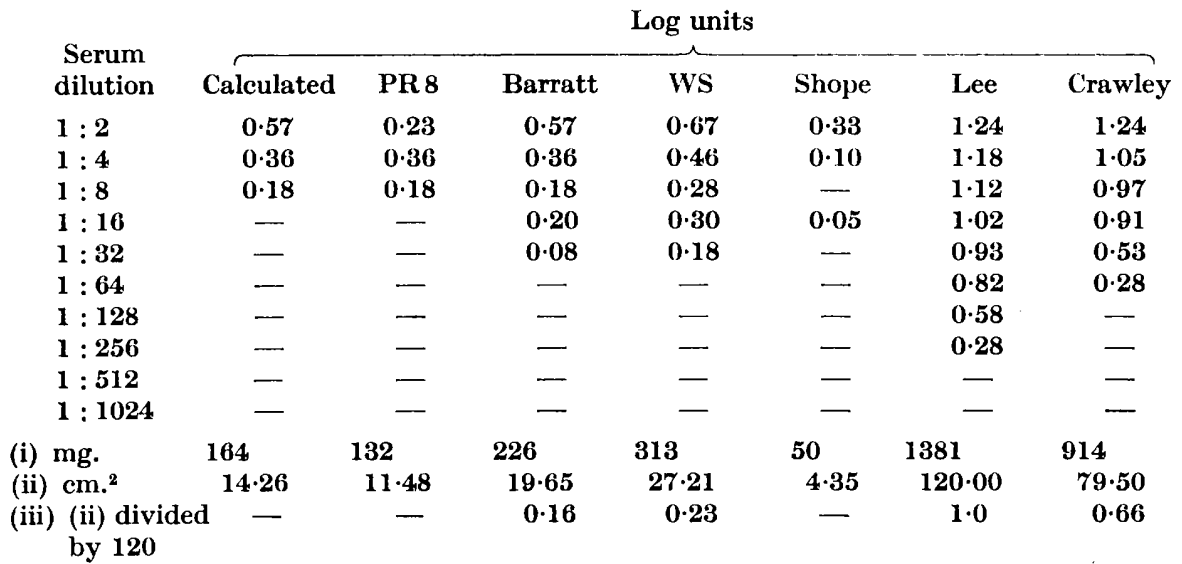

of PR 8 and Barratt in Table $7 a$ are $\mathbf{0 . 5 5}$ and 0 so that the arithmetic mean is 0.28. It is clear that all of the strains examined are different, though Lee and Crawley are closely similar and WS and Barratt are fairly closely related. Apparently there is some slight relationship between the WS strain and the two strains of Influenza B virus.

Table 7 (a). Comparison of six strains of influenza virus. Degree of complement fixation expressed by an index number, homologous $=1 \cdot 0$

\begin{tabular}{|c|c|c|c|c|c|c|}
\hline \multirow[b]{2}{*}{ Antigens } & \multicolumn{6}{|c|}{ Sera } \\
\hline & Ws & BAR & PR 8 & Shope & Lee & CRA \\
\hline WS & $1 \cdot 0$ & 0.53 & $0 \cdot 61$ & 0.57 & $0 \cdot 23$ & $0 \cdot 25$ \\
\hline BAR & $0 \cdot 63$ & $1 \cdot 0$ & 0.55 & 0.57 & $0 \cdot 16$ & 0 \\
\hline PR 8 & 0.26 & 0 & $1 \cdot 0$ & $0 \cdot 14$ & 0 & 0 \\
\hline Shope & 0 & $\mathbf{0}$ & 0.29 & $1 \cdot 0$ & 0 & 0 \\
\hline Lee & 0 & 0 & 0 & $0 \cdot 14$ & $1 \cdot 0$ & $0 \cdot 84$ \\
\hline CRA & 0 & 0 & 0 & $0 \cdot 14$ & 0.66 & $1 \cdot 0$ \\
\hline
\end{tabular}

Table 7(b). Comparison of six strains of influenza virus. Arithmetic mean of cross-reactions

$\begin{array}{ccccccc}\text { Antigens } & \text { WS } & \text { BAR } & \text { PR 8 } & \text { Shope } & \text { Lee } & \text { CRA } \\ \text { WS } & \mathbf{1 \cdot 0} & 0.58 & 0 \cdot 44 & 0 \cdot 28 & 0 \cdot 11 & 0 \cdot 12 \\ \text { BAR } & - & 1 \cdot 0 & 0 \cdot 28 & 0 \cdot 28 & 0 \cdot 08 & 0 \\ \text { PR 8 } & - & - & 1 \cdot 0 & 0 \cdot 22 & 0 & 0 \\ \text { Shope } & - & - & - & 1 \cdot 0 & 0 \cdot 07 & 0.07 \\ \text { Lee } & - & - & - & - & 1 \cdot 0 & 0.75 \\ \text { CRA } & - & - & - & - & - & 1 \cdot 0\end{array}$


By similar methods the Barratt 1947 A strain was compared with the Williams strain isolated during the same epidemic, and also with the Rhodes strain isolated in New York in 1947 (Table 8). The three strains are identical.

Table 8. Comparison of three strains of influenza virus isolated in 1947. Arithmetic mean of cross-reactions

\begin{tabular}{lccc}
\multicolumn{4}{c}{ Arithmetic mean of cross-reactions } \\
BAR & BAR & WIL & RHO \\
WIL & $\mathbf{1 . 0}$ & $\mathbf{0 . 9 7}$ & $\mathbf{0 . 9 7}$ \\
RHO & - & $\mathbf{1 . 0}$ & - \\
& - & - & $\mathbf{1 . 0}$
\end{tabular}

\section{DISCUSSION}

In the comparison of a number of strains of influenza virus it has not been possible to demonstrate strictly reciprocal cross-reactions. Because of this it is unlikely that there is a mosaic of antigens variously represented in the individual strains.

The interpretation of cross-reactions is bound to remain hypothetical until chemical details are known, but it seems reasonable to regard the influenza strains as a number of related but in most cases not identical structures, and the cross-reactions as due to the diversity of antibodies produced against the configuration as a whole (cf. Landsteiner, 1945).

The relationships between the strains examined may be understood by considering a number of theoretical strains. A strain $\alpha$ is presumed to be identical with a strain $\beta$ when the standard $\alpha$ antigen gives with the $\beta$ antiserum the homologous serum titre-and vice versa. Under such circumstances the amounts of complement fixed maximally will necessarily be the same in both cases, here chosen at $1.0 \mathrm{~mm} .^{3}$ When strains are entirely dissimilar the zone of fixation falls within the calculated non-significant fixation.

Of strains which are similar but not identical there are two groups. In the first group, strain $\gamma$ is similar to but not identical with strain $\beta$ when the standard $\gamma$ antigen is matched with the $\beta$ anti-serum and the serum titre is less than the homologous titre. This is taken to mean that only some of the antibodies are of a sufficiently good fit to react with the antigen. Owing to the large excess of serum antibodies available there are still sufficient of these antibodies at a serum dilution of $1 / 2$ to enable the antigen to fix the standard $1.0 \mathrm{~mm} .{ }^{3}$ of complement (Fig. 6, BAR).

In the second group, strain $\delta$ is even more unlike the $\beta$ strain, since not only are the available antibodies in the $\beta$ serum merely a part of those with which the homologous antigen reacts, as shown by the lower serum titre, but also the maximal complement fixed is less than $1.0 \mathrm{~mm} .^{3}$, suggesting that the $\delta$ antigen is heterogeneous and that only certain elements are able to react with certain components of the $\beta$ antibody population (Fig. 6, PR 8).

This distinction as to whether the whole of the standard amount of complement is fixed or not might have been used as a method of classification within the $\mathbf{A}$ and $\mathbf{B}$ strains. But as the cross-reactions are not reciprocal we have had to accept the mean of the observed cross-reactions. 
Friedewald (1944) has studied the antigenic composition of influenza virus by means of antibody absorption tests. However, the value of this difficult technique seems rather doubtful if one considers the cross-reactions as being due to diversity of antibodies produced against the configuration as a whole.

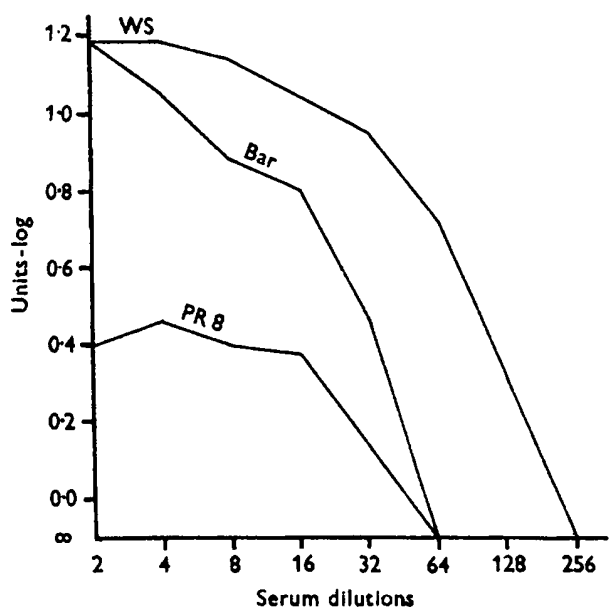

Fig. 6. WS immune serum titrated with three standard antigens to show the fixation of a closely similar strain (BAR) and the fixation of a slightly related strain (PR 8).

For two heterologous strains will only react with the same group of antibodies if they are themselves identical-a fact which can be demonstrated in simpler ways.

We have not attempted a classification of the influenza virus strainsa task which would demand the detailed examination of a large number of strains. The method proposed has, however, enabled us to compare strains with accuracy, and paves the way for a useful classification.

\section{REFERENCES}

Brown, G. C. (1943). The complementary activity of mouse-serum. J. Immunol. 46, 319.

Bukantz, S. C., Rein, C. R. \& Kent, J. F. (1946). Studies in complement fixation. II. Preservation of sheep's blood in citrate dextrose mixtures (modified Alsever's solution) for use in the complement fixation reaction. J. Lab. clin. Med. 31, 394.

Burnet, F. M., Beveridge, W. I. B., McEwin, J. \& Boake, W. C. (1945). Studies on the Hirst haemagglutination reaction with Influenza and Newcastle disease viruses. Aust. J. exp. Biol. med. Sci. 23, 177.

Casals, J. \& Palacios, R. (1841). The complement fixation test in the diagnosis of virus infections of the central nervous system. J. exp. Med. 74, 409.

Francis, T. \& Magill, T. P. (1938). Antigenic differences in strains of epidemic influenza virus. II. Cross-immunization tests in mice. Brit. J. exp. Path. 19, 284.

Francis, T. \& Salk, J. E. (1942). A simplified procedure for the concentration and purification of Influenza virus. Science, 96, 499.

Francis, T., Salk, J. E. \& Brace, W. M. (1946). Protective effect of vaccination against epidemic influenza. J. Amer. med. Ass. 131, 275. 
Journal of General Microbiology, Vol. 3, No. 1

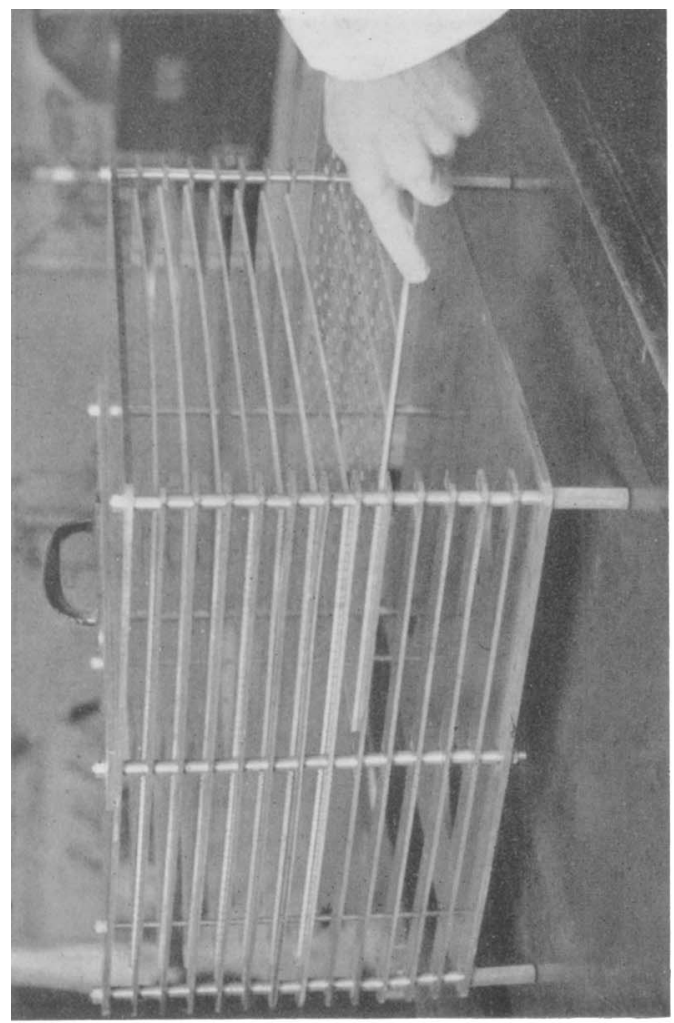

$\stackrel{0}{0}$
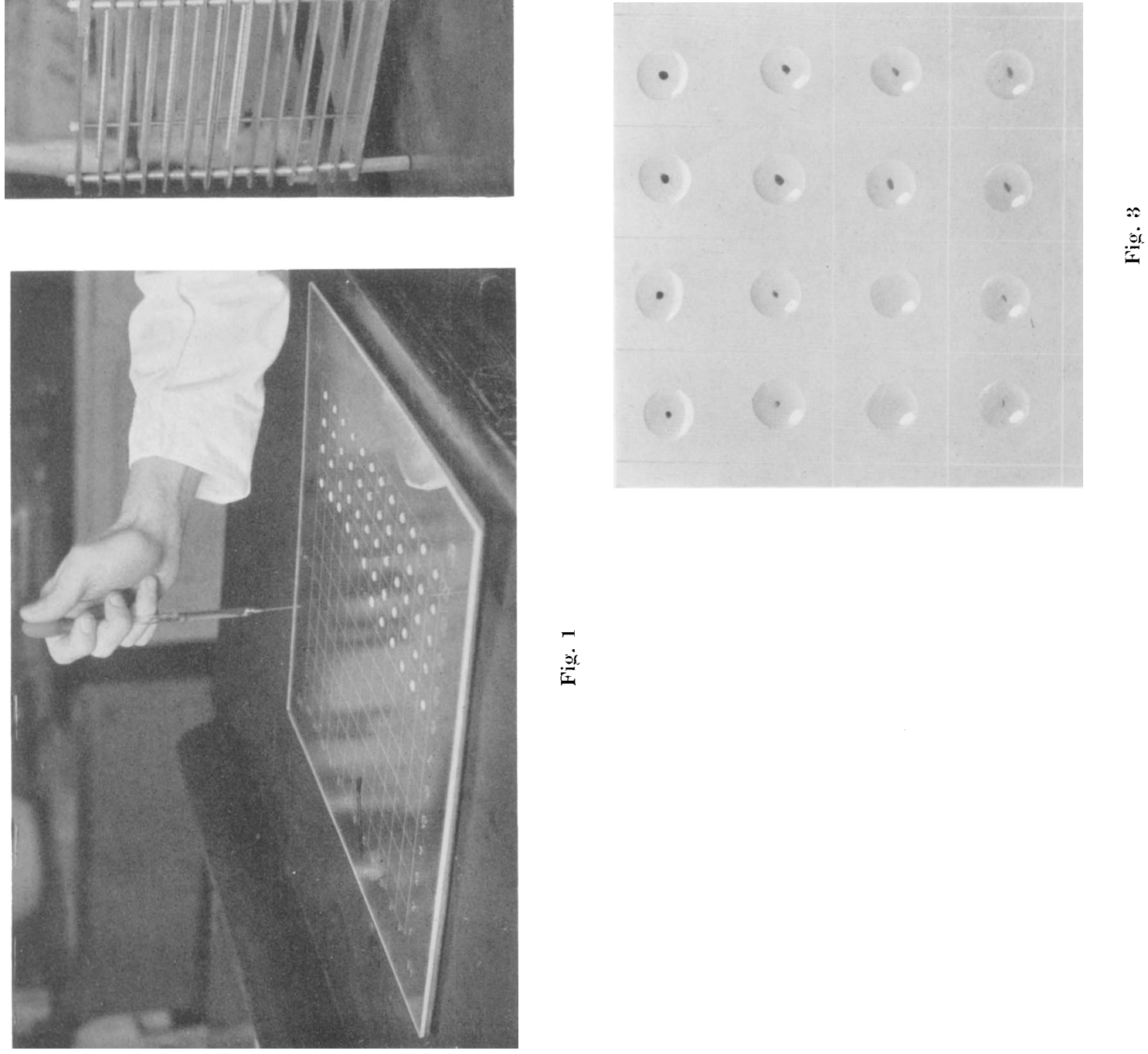

is

F. Fulton \& K. R. Dumblil-The serological comparison of strains of influenza virus. Plate: 1 
Friedewald, W. F. (1943). The immunological response to influenza virus infection as measured by the complement fixation test. J. exp. Med. 78, 347 .

Friedewald, W. F. (1944). Qualitative differences in the antigenic composition of influenza A virus strains. J. exp. Med. 79, 633.

Hirst, G. K. (1943). Studies of antigenic differences among strains of influenza $A$ by means of red cell agglutination. J. exp. Med. 78, 407.

HrRST, G. K. (1947). Studies on the mechanism of adaptation of influenza virus to mice. J. exp. Med. 86, 357.

Laidlaw, P. P., Smith, W., Andrewes, C. H. \& Dunkin, G. W. (1935). Influenza: the preparation of immune sera in horses. Brit. J. exp. Path. 16, 275.

LANDSTEINER, K. (1945). The Specificity of Serological Reactions (revised edition), p. 116. Cambridge, Mass. : Harvard University Press.

Magill, T. P. \& Francis, T. (1938). Antigenic differences in strains of Epidemic Influenza virus. I. Cross-neutralization tests in mice. Brit. J. exp. Path. 19, 273.

Mayer, M. M., Osler, A. G., Bier, O. G. \& Heidelberger, M. (1946). The activating effect of magnesium and other cations on the haemolytic function of complement. J. exp. Med. 84, 535.

SALK, J. E. (1944). A simplified procedure for titrating haemagglutinating capacity of influenza virus and the corresponding antibody. J. Immunol. 49, 87 .

Smith, W. \& ANDrewes, C. H. (1938). Serological races of influenza virus. Brit. J. exp. Path. 19, 293.

StuART-Harris, C. H. (1943). Observations on the agglutination of fowl red cells by influenza viruses. Brit. J. exp. Path. 24, 33.

Wadsworth, A., Maltaner, F. \& Maltaner, E. (1938). Quantitative studies of the complement-fixation with syphilitic serum and tissue extract: technic of the practical quantitative test. J. Immunol. 35, 217.

Wiener, M., Henle, W. \& Hente,.G. (1946). Studies on the complement fixation antigens of influenza viruses types A and B. J. exp. Med. 83, 259.

\section{EXPLANATION OF PLATE}

Fig. 1. Technique for complement fixation: setting out drops on a Perspex sheet.

Fig. 2. Technique for complement fixation: rack to hold 12 Perspex sheets.

Fig. 3. Technique for complement fixation: to show the method of reading the test. Where the erythrocytes have not been haemolysed they have collected into a central dot. 